\title{
Upper mantle velocity structure in the western Pacific rim estimated from short-period recordings at Matsushiro Seismic Array System
}

\author{
Mamoru Kato* and Ichiro Nakanishi \\ Department of Geophysics, Kyoto University, Kyoto 606-8502, Japan
}

(Received May 11, 1999; Revised May 20, 2000; Accepted June 2, 2000)

\begin{abstract}
We investigate lateral variation of the upper mantle $P$-wave velocity structure in the western Pacific rim using travel times of $P$ phases from regional shallow events. Onsets of direct and later arrivals are manually picked up from short-period waveforms at Matsushiro Seismic Array System in central Japan by consulting the correlation among the waveforms at seven array stations. For the path along Kurile and Alaska seismic zones, observed first arrivals of shallow events $(d=5-50 \mathrm{~km})$ are well explained by a standard travel time table for Japan. Observations provide no strong evidence of a distinct low-velocity zone in the uppermost mantle, and triplicated branches are adequately explained by a slight modification of model 12 by Sugiyama and Nakanishi $(1989,1999)$. Observed travel times of direct $P$ phases from events along the eastern and western Philippine Sea are slightly larger at around $15^{\circ}$ and slightly smaller at around $25^{\circ}$, and the upper mantle is slower and the transition zone and uppermost lower mantle faster in the eastern and western Philippine Sea than in the northwestern Pacific. Such differences could reflect a high temperature in the upper mantle, and accumulation of subducted material at the base of transition zone as a result of the past subduction.
\end{abstract}

\section{Introduction}

The most direct information of the velocities in the upper mantle can be derived from travel times and apparent velocities of seismic phases. An abrupt change of apparent velocity of direct $P$ phase (e.g., Kishimoto, 1956) and triplicated arrivals in regional distances (e.g., Niazi and Anderson, 1965; Walck, 1984) have been used to construct upper mantle velocity models. Several velocity models have been presented for the western Pacific region, some of which are constructed with measurements of travel times and apparent velocities of $P$ phase (Kanamori, 1967; Fukao, 1977; Inatani and Kurita, 1980; Sugiyama and Nakanishi, 1989 and 1999), some are by direct waveform analyses (Erdögan and Nowack, 1993; Yamazaki and Hirahara, 1996).

Two major issues concerning the upper mantle velocity structure in oceanic regions are properties of the low-velocity zone in the uppermost mantle, and depths to and magnitudes of velocity jump at the transition zone discontinuities. The low-velocity zone appears to be an indispensable feature in the oceanic region (e.g., Turcotte and Schubert, 1982; Sato et al., 1989), and its possible absence beneath the matured northwestern Pacific basin (e.g., Sugiyama and Nakanishi, 1989 and 1999) would be an important constraint on the potential temperature in the convective oceanic mantle, though recent evidences strongly suggest that the origin of the lowvelocity zone may not be solely thermal (Karato, 1995; Hirth

*Present address: Earthquake Research Institute, University of Tokyo, 1-1-1 Yayoi, Bunkyo, Tokyo 113-0032, Japan.

Copy right (C) The Society of Geomagnetism and Earth, Planetary and Space Sciences (SGEPSS); The Seismological Society of Japan; The Volcanological Society of Japan; The Geodetic Society of Japan; The Japanese Society for Planetary Sciences. and Kohlstedt, 1996; Gaherty et al., 1999; Kato and Jordan, 1999). Rapid increases of velocities approximately at $410 \mathrm{~km}$ and $660 \mathrm{~km}$ depths are often interpreted as signature of phase transitions of the olivine species (Ringwood, 1975; Bina, 1991). Lateral variation of their depths and magnitudes of velocity jump might be used to constrain the mineralogy and the temperature of the upper mantle.

We investigated the velocity structure of the upper mantle beneath the western Pacific rim by studying travel times of direct $P$ phase from regional events. Variations of the upper mantle velocities among regional models are larger than those in global tomographic models (e.g., Fukao et al., 1992; Su et al., 1994), and regional models are needed to further understand the lateral variation of physical properties in the mantle (Nolet et al., 1994). Regional variation has been often discussed by comparing models that are derived using different types of techniques and different types of data (Nolet et al., 1994). One of the scopes of this study is to investigate how much we can infer regional variation from short-period recordings by equalizing characteristics of data and analysis technique.

Our data sets comprise travel times of $P$ phases which are measured from waveform data recorded at Matsushiro Seismological Array Systems (MSAS) in Japan. MSAS is located approximately at the intersection of three subduction zone arcs, Kurile-Alaska, Izu-Mariana, and RyukyuPhilippines, and the data from MSAS would be suitable to investigate variation of upper mantle velocity structure in these three regions. Observed travel times of the first arrivals in three regions are consistent with a standard travel time table in Japan (Hamada, 1984). We present a onedimensional $P$ wave velocity model for the Kurile-Alaska 
Table 1. Stations of MSAS.

\begin{tabular}{lccrrrc}
\hline Code & Latitude $\left({ }^{\circ} \mathrm{N}\right)$ & Longitude $\left({ }^{\circ} \mathrm{E}\right)$ & Dep & Elev & Vp & T \\
\hline TKM & 36.560 & 138.242 & 46.7 & 598 & 6.1 & 1.00 \\
JZO & 36.522 & 138.250 & 43.3 & 616 & 3.6 & 1.02 \\
SGD & 36.539 & 138.319 & 75.4 & 1231 & 5.3 & 0.98 \\
DIR & 36.482 & 138.298 & 53.0 & 838 & 4.8 & 1.02 \\
IRK & 36.468 & 138.254 & 43.3 & 761 & 4.1 & 0.97 \\
MAT & 36.543 & 138.207 & 0.0 & 406 & 6.0 & 1.01 \\
WDR & 36.487 & 138.214 & 65.0 & 961 & 4.3 & 1.01 \\
\hline
\end{tabular}

Dep: Depth of sensor measured from surface (meter). Elev: Elevation of sensor (meter). Vp: Velocity of boring sample (km/sec). T: Characteristic period of vertical component sensor (second). From Osada et al. (1984).

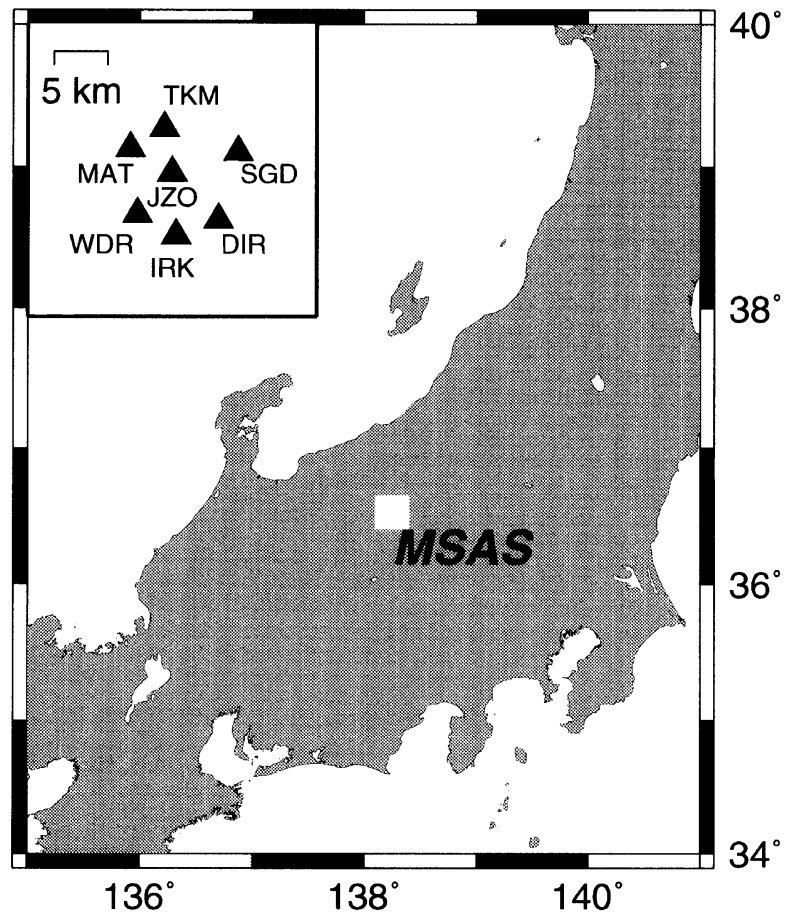

Fig. 1. Location of Matsushiro Seismic Array System. See also Table 1. Inset map shows the location of array stations. Sensors are located in borehole at all stations, except MAT at which sensors are located in a horizontal vault.

path. Observed travel times of initial $P$ arrivals for two Philippine Sea paths differ slightly from the prediction of our Kurile-Alaska model, and this difference should indicate that the upper mantle beneath these Philippine Sea paths is characterized by the slow and possibly heterogeneous uppermost mantle and the fast transition zone and uppermost lower mantle.

\section{Data}

MSAS, located in central Japan (Fig. 1), is operated by Japan Meteorological Agency (Osada et al., 1984). MSAS consists of seven stations and an average distance between stations is approximately 5 kilometers (Fig. 1, Table 1). Each station is equipped with an identical three-component

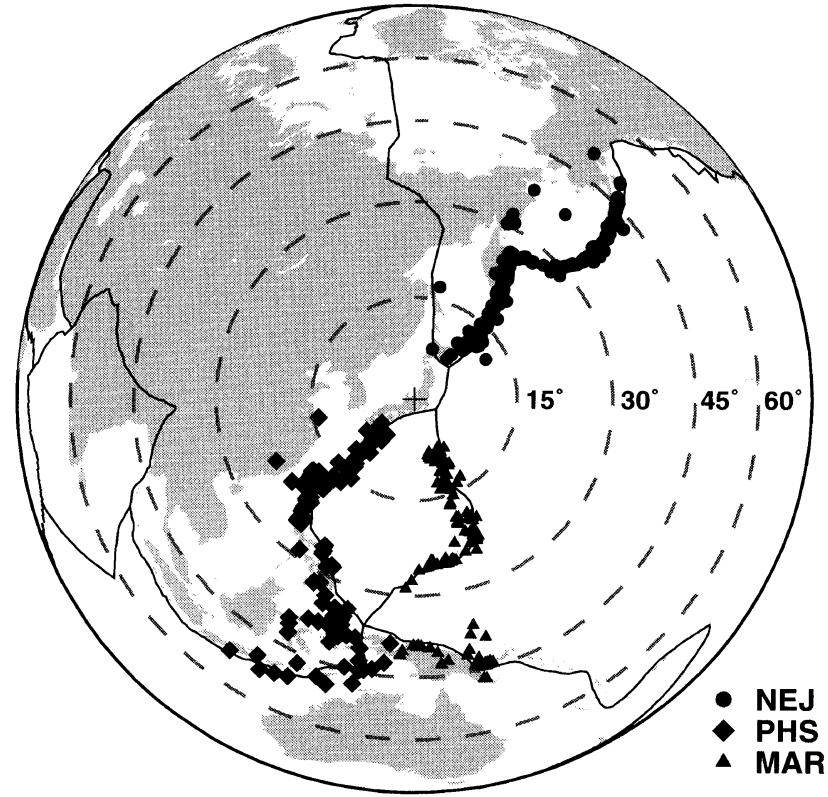

Fig. 2. Location of events. Circles, diamonds, and triangles denote events for NEJ, PHS, and MAR paths, respectively. Dash lines represent equidistant lines for epicentral distances of $15,30,45$, and 60 degrees. Orthographic projection is used, the center of projection being at MSAS.

velocity-type short-period sensor, whose characteristic frequency is approximately $1 \mathrm{~Hz}$, responses being flat between 2 and $10 \mathrm{~Hz}$ (Table 1). Sampling frequency is $80 \mathrm{~Hz}$ (Osada et al., 1984). Sensors at MAT and other six stations are installed in the horizontal vault and the boreholes at 40 to 70 meters depth (Table 1), respectively. We use records of vertical component.

Surface geology beneath the array stations appears to be very heterogeneous; the compressional velocities measured with the drilled samples vary from 3.6 to $6.1 \mathrm{~km} / \mathrm{s}$ (Osada et al., 1984), and a refraction survey revealed substantial topography of subsurface layer boundaries in the crust (Asano et al., 1969). Simple two-layer crust models have not been fully successful in explaining observed travel time residuals within the array (Nagai and Kashiwabara, 1985; Maki et al., 1987). Complexity of the surface and topography geology 
results in strong site effects at array stations (Kato et al., 2000), which hinder application of conventional array techniques, such as delay-sum stacking or semblance analysis. We then assume MSAS as a network with small inter-station distances, and arrivals of later phases are visually inspected and manually picked up considering the correlation among waveforms.

Source regions in our study are three arcs in the western Pacific rim. The northeastern Japan (NEJ) path spans the Kurile arc to the Alaska seismic zones, the western Philippine Sea (PHS) path does the Ryukyu-Taiwan-Philippine arc, and the Mariana (MAR) path does Izu-Bonin to Mariana arc and the New Guinean seismic zones (Fig. 2). High-frequency recordings of shallow events $(d=0-100 \mathrm{~km})$ are used in this study. Event sizes are between mb 5.0 and 6.8. Quality and quantity of NEJ data set are best among them and we mainly focus on this data set in the study. Waveforms of several hundred events are initially selected for each path, and quality of waveforms is visually evaluated based on signalto-noise ratio in the raw records, and then based on the correlation among seven waveforms. Onsets of direct $P$ phase are picked up manually from the filtered records with a band of $0.1-2.5 \mathrm{~Hz}$ (Fig. 3). We did not deconvolve the empirical source time function (e.g., Yamazaki and Hirahara, 1996), considering the limited bandwidth in our data and probable contamination of site effects (Kato et al., 2000); correlation among these regional and teleseismic waveforms becomes low after a couple of cycles following the onset of $P$ phase, even though the inter-station distances are small. Examples of array waveforms for the NEJ dataset are given in Fig. 4.

Strong site effects also hinder easy identification of later arrivals. In previous studies (e.g., Fukao, 1977; Inatani and Kurita, 1980; Sugiyama and Nakanishi, 1989 and 1999), apparent velocities are measured in the record sections that span more than a couple of degrees, which are then used to identify later phase branches. Due to a small diameter of MSAS, which is approximately $10 \mathrm{~km}$, it is difficult to conclusively identify any branches with waveforms from a single event solely based on the difference of apparent velocities. Our approach in this study is to visually examine the correlation of the waveforms and identify later arrivals. We also compare measurements for events with similar epicentral distances to identify possible branches. Such approach should be effective in reducing the possibility that an incoherent arrival of energy due to scattering beneath the array would be erroneously identified as a phase from the deep upper mantle.

All travel time measurements are corrected for the source depth using a standard velocity model for the Japanese Islands (Hamada, 1984). Due to a larger scatter in the depthcorrected travel times, and we first excluded data from the events whose depths are deeper than $50 \mathrm{~km}$. Our measurements are mostly well explained by this standard travel time table (Fig. 5), except for data from the shallowest events (0-5 $\mathrm{km})$. We speculate that this disagreement is due to the mislocation of the shallow events, specifically of the source depth. Relocation of these events would not solve the problem unless arrival times of $P$ and depth phases are reexamined with the original waveform data. We therefore removed all waveforms of shallowest events from the dataset. Final dataset in-
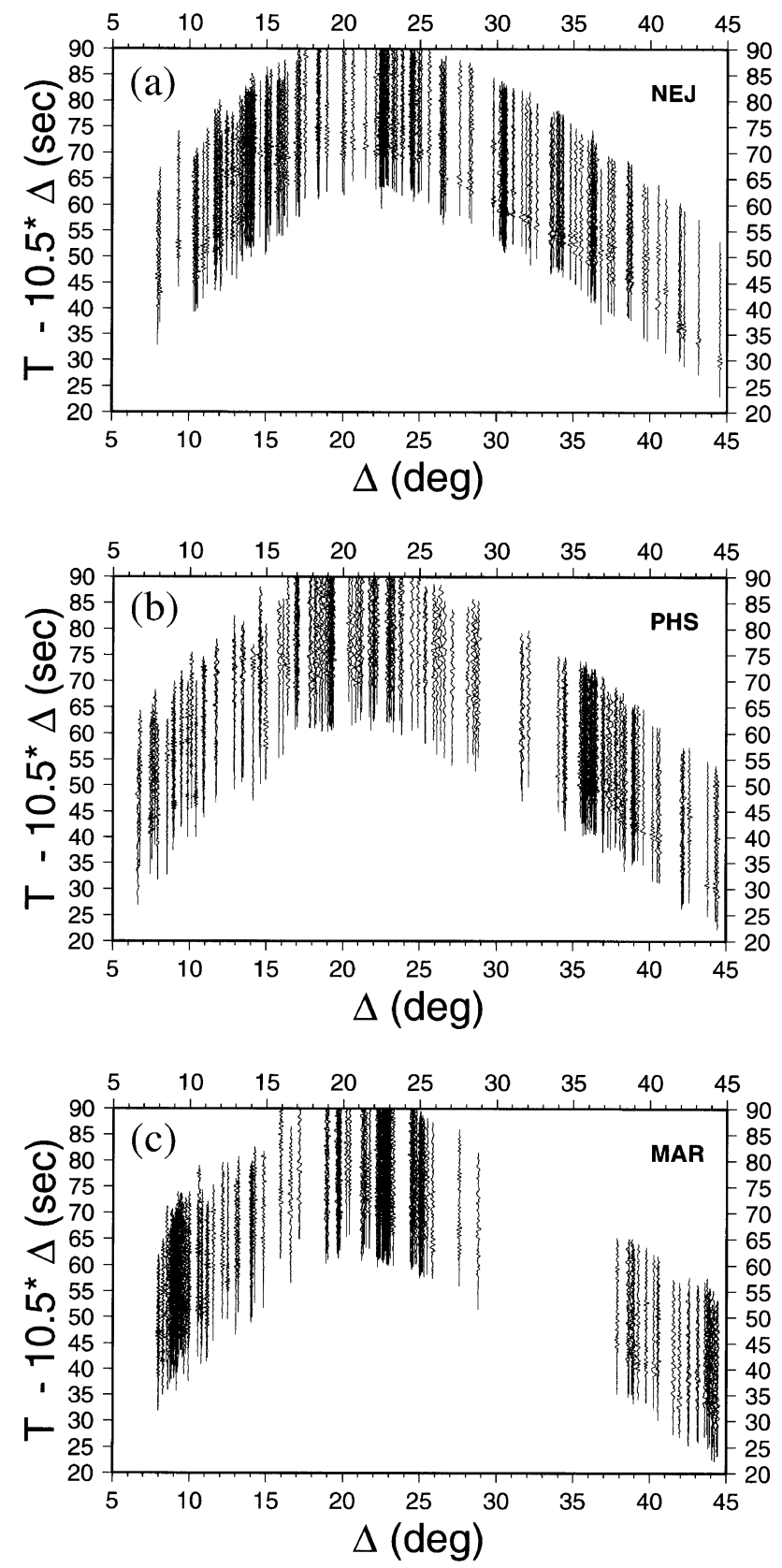

Fig. 3. Record section of observed waveforms at station MAT for NEJ (a) PHS (b), and MAR (c) paths. Each trace is filtered $(0.1-2.5 \mathrm{~Hz})$ and is normalized by its respective maximum amplitude. Reduction slowness of $10.5 \mathrm{~second} /$ degree is used.

cludes picks from 276 events for the NEJ path, whose depths are thus between 5 and $50 \mathrm{~km}$.

\section{Model for the NEJ Path}

Travel times of $P$ phase from regional events alone do not constrain velocities in the uppermost mantle tightly, and several assumptions on crustal and lithospheric structure and velocities are needed to be employed. We first examine several published models for the Kurile-Alaska path (Kanamori, 1967; Fukao, 1977; Erdögan and Nowack, 1993; Yamazaki and Hirahara, 1996; Sugiyama and Nakanishi, 1989 and 1999) as well as those for the other part of Pacific (Walck, 1984 and 1985; Gaherty et al., 1996), which are tested whether they could explain several possible branches that are 
a) evt.91122008

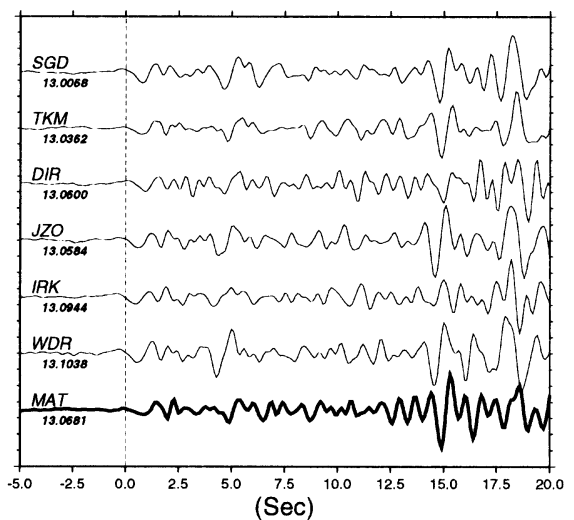

b) evt. 89070809

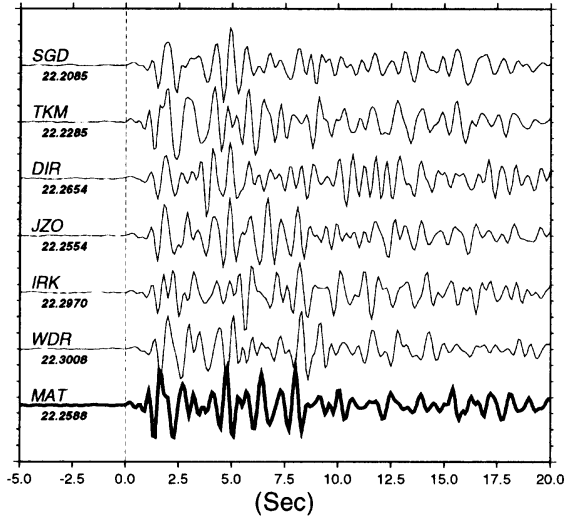

c) evt.91030821

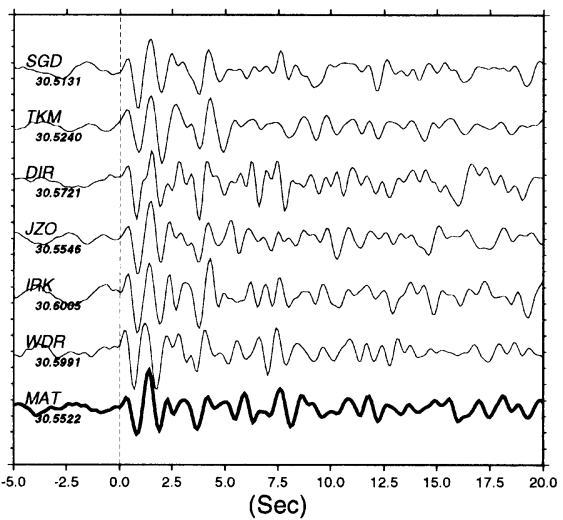

d) evt.84081401

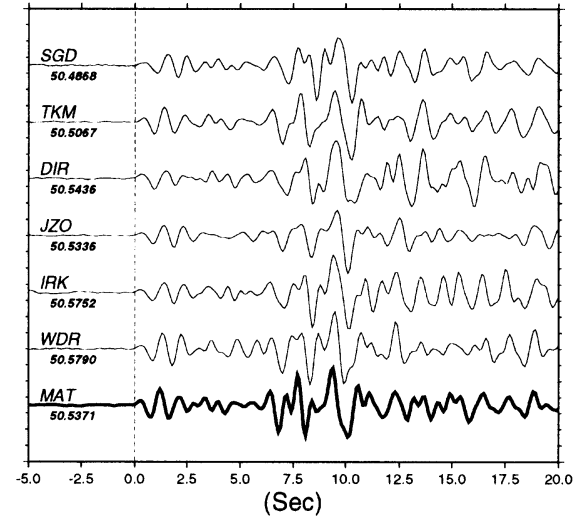

Fig. 4. Example waveforms for the NEJ dataset. Traces are plotted on the same scale for each event. The origin of the plot is set at the $P$ arrival time for each record. Epicentral distances are plotted beneath the station code. a) Records from an event at approximately 13 degrees from MSAS (45.13N, $151.25 \mathrm{E}, 48 \mathrm{~km}$ ). The phase at $14 \mathrm{sec}$. is example for the A branch in Fig. 6(a). b) Records from an event at approximately 22 degrees (52.87N, $159.78 \mathrm{E}$, $18 \mathrm{~km})$. c) Records from an event at approximately 30 degrees $(60.91 \mathrm{~N}, 167.29 \mathrm{E}, 10 \mathrm{~km}) \mathrm{d})$ Records from an event at approximately 50 degrees $(61.81 \mathrm{~N}$, $149.11 \mathrm{~W}, 13 \mathrm{~km})$. Even for such teleseismic distances, the correlation of the waveforms within the array is low, which indicates that effects of the sites cannot be negligible at MSAS (Kato et al., 2000).

identified on the observed $\Delta$-T plot as well as travel times of direct $P$ phase. Our approach differs from those in previous studies in that the observed travel times are not binned according to their epicentral distances or their relative travel times from direct $P$ phase; proper binning of data points should require good prior knowledge on the location of triplicated branches on the $\Delta$-T plot. Observed travel time curve appears to be continuous between 10 and 15 degrees. Large scatter in these distances should be related to the heterogeneous structure in the uppermost mantle, and observations could be explained with a model without a distinct low-velocity zone in the uppermost mantle. Model 12 of Sugiyama and Nakanishi (1989, 1999), which is a slight modification of ARC-TR (Fukao, 1977) and is constructed for the path connecting the Kurile-Alaska arc and the stations in Hokkaido, explains travel times of direct $P$ phase as well as some later phases fairly well (Fig. 6(a)), though the small difference between the prediction and observation is recognizable in the distance range between $25^{\circ}$ and $35^{\circ}$.

Three clusters of later arrivals are not at all well predicted by Model 12 and appear to be out of place. Two of them are located in the typical epicentral range of the triplication that are caused by the discontinuities in the mantle transition zone; slownesses are as large as 10.7-10.8 sec/degree for cluster A between 13 to 17 degrees, and as small as 9.8-9.9 sec/degree for cluster B between 23 and 27 degrees. Associating these branches with direct $P$ phases requires velocities in the transition zone to be inconsistent with the constraint from the mantle mineralogy (e.g., Ita and Stixrude, 1992), and is thus quite difficult. These "branches" should be associated with depth phases, such as $p P$ and $s P$. Considering the range in the event depths in our data and the strategy of identification of later phases, the possibility of identifying false branch remains, and these linear alignments should be purely coincidental and artificial, and would not be related to the triplication of direct $P$ phase. The third one is located at approximated at $30^{\circ}$ (C in Fig. 6), which would also be related to depth phases or scattered wavefield excited in the source region.

Model sn12c is our model for the Kurile-Alaska path (Fig. 7, Table 2), which is a slight modification of Model 12 (Sugiyama and Nakanishi, 1989 and 1999). Since our observations are adequately well explained by Model 12, we try to keep the structural features of Model 12, such as depths 
Table 2. Model sn12c.

\begin{tabular}{|c|c|}
\hline Depth $(\mathrm{km})$ & $\mathrm{Vp}(\mathrm{km} / \mathrm{s})$ \\
\hline 0 & 5.57 \\
\hline 15 & 5.57 \\
\hline 33 & 6.50 \\
\hline 33 & 7.84 \\
\hline 95 & 8.10 \\
\hline 165 & 8.10 \\
\hline 200 & 8.36 \\
\hline 205 & 8.41 \\
\hline 225 & 8.40 \\
\hline 240 & 8.40 \\
\hline 260 & 8.41 \\
\hline 280 & 8.44 \\
\hline 300 & 8.47 \\
\hline 320 & 8.52 \\
\hline 340 & 8.57 \\
\hline 360 & 8.64 \\
\hline 385 & 8.74 \\
\hline 400 & 9.27 \\
\hline 520 & 9.72 \\
\hline 660 & 10.23 \\
\hline 670 & 10.29 \\
\hline 690 & 10.39 \\
\hline 707 & 10.83 \\
\hline 800 & 11.03 \\
\hline 900 & 11.19 \\
\hline 1000 & 11.34 \\
\hline 1200 & 11.64 \\
\hline
\end{tabular}

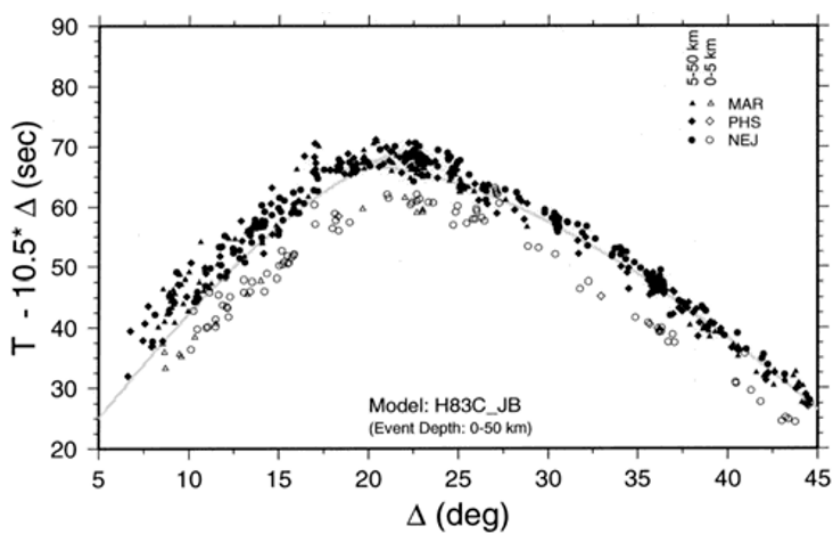

Fig. 5. Picked travel times of the first arrivals. Circles, diamonds, and triangles represent data from NEJ, PHS, and MAR data set, respectively; open and filled symbols are of shallow $(d=0-5 \mathrm{~km})$ and deep $(d=5-50 \mathrm{~km})$, respectively. Solid line indicates $P$ arrival times for the standard time table of Hamada (1984). Note that there is an offset of approximately 5 seconds for some data points, all of which are of shallow $(0-5 \mathrm{~km})$ events.

of discontinuities, as much as possible, and made only three minor modifications. First, the velocity is slightly lowered between 185 and $400 \mathrm{~km}$. This is to explain travel times of the first arrivals between 15 and 20 degrees. Second, the velocity gradient between the $410-\mathrm{km}$ and $660-\mathrm{km}$ discontinuities is simplified. Sugiyama and Nakanishi $(1989,1999)$ used direct measurements of slowness at 20 degrees to constrain velocity gradients in the transition zone. Our observations are made at the surface and events are shallow, and do not provide such constraint on the deep fine structure in the
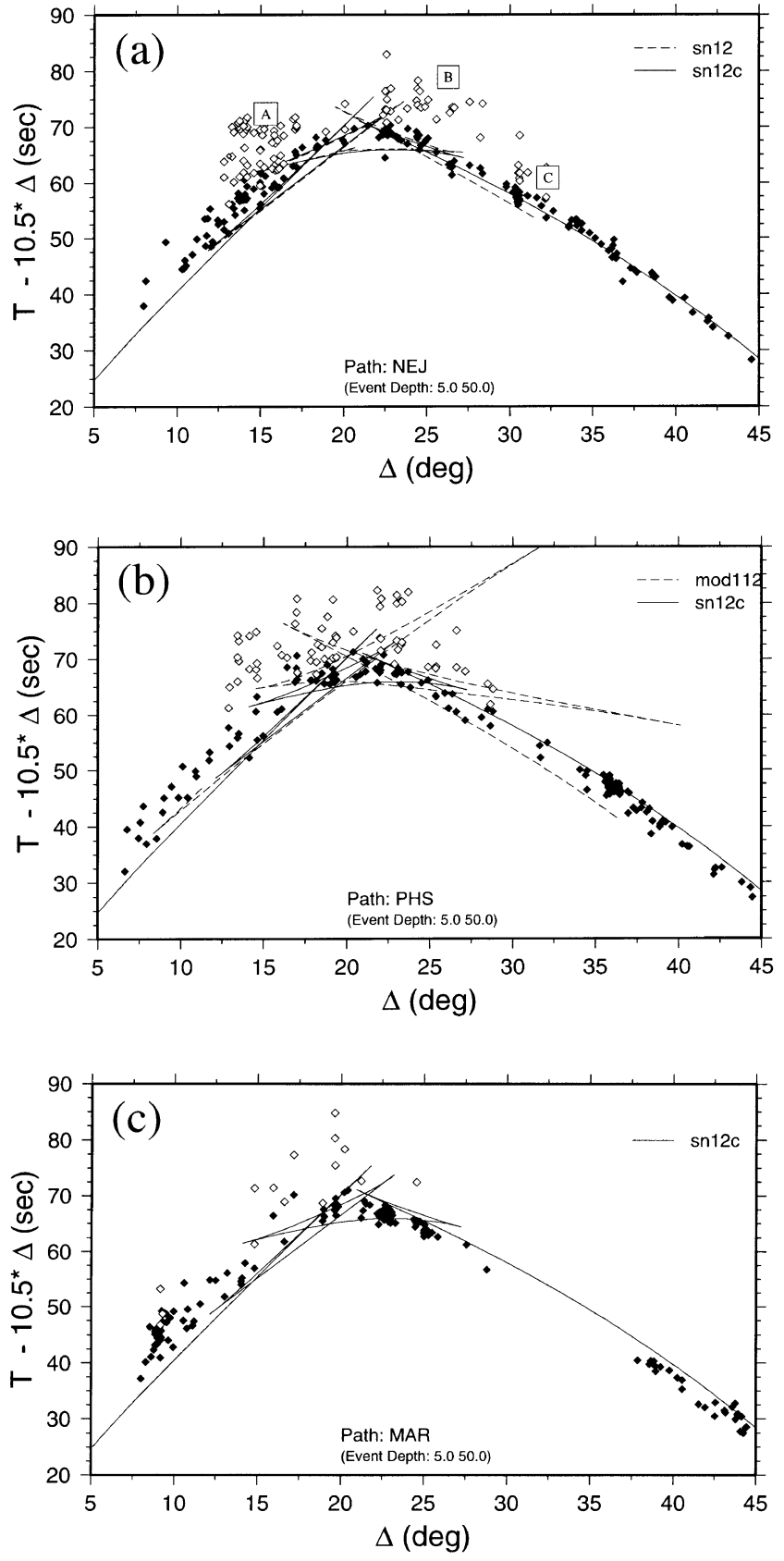

Fig. 6. All picks of travel time for NEJ (a), PHS (b), and MAR (c) data sets. Data from events whose depths are between 5 and $50 \mathrm{~km}$ are plotted. First arrivals are shown with filled diamonds, and later arrivals are shown with open diamonds. Also plotted is the predicted travel time curve for (a) model 12 (Sugiyama and Nakanishi, 1989 and 1999), and model sn12c, (b) model 112 (Inatani and Kurita, 1980), and model sn12c, and (c) model sn12c. Inset letters, A to C, in (a) signify clusters of data points which appear not to be well explained by model 12 . See text for details.

transition zone (e.g., Tajima and Grand, 1995; Brudzinski et $a l ., 1997)$, and our preference is a simple model. The third modification is the reduction of velocity jump of the $660-\mathrm{km}$ discontinuity (at approximately $700 \mathrm{~km}$ ) and an increase of velocity gradient in the uppermost lower mantle. This modification is required to match travel time in the distance range of 25 degrees and beyond. Though the observations show some scatter, model sn12c explains the observations well on average (Fig. 6(a)). 


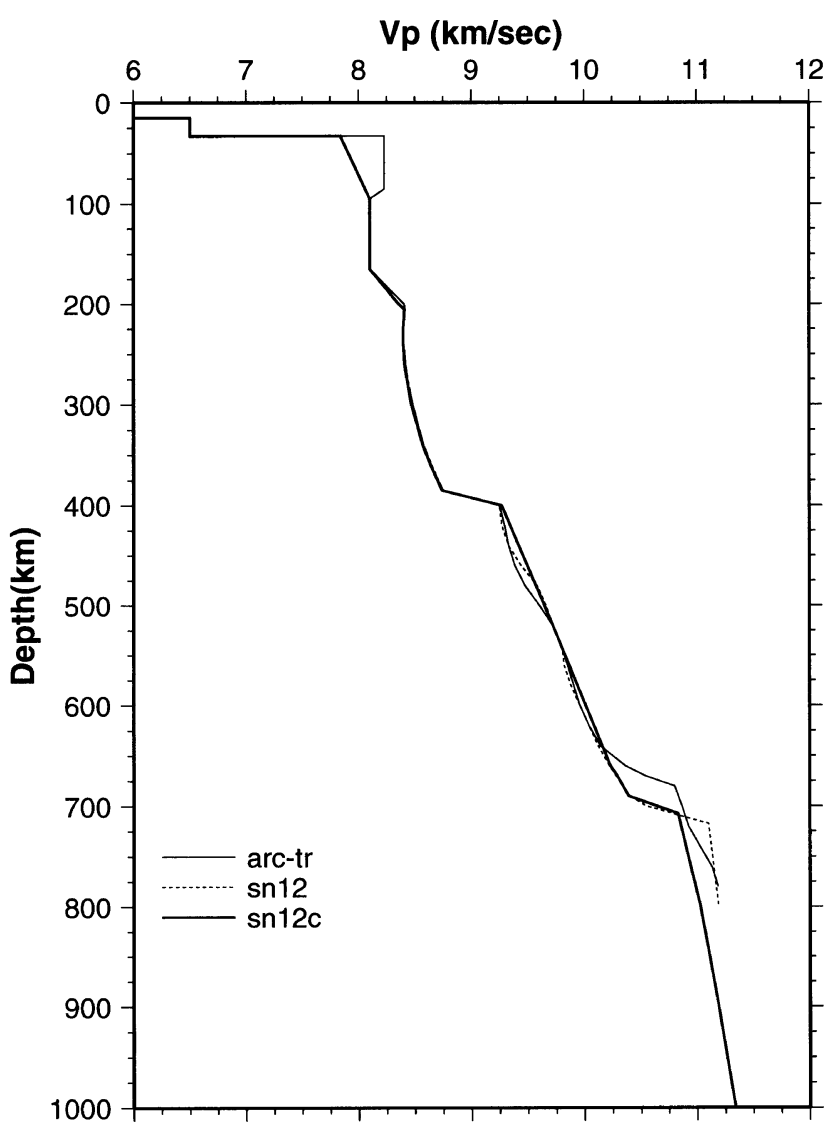

Fig. 7. Our velocity model for the NEJ path, sn12c. Also plotted are model 12 (Sugiyama and Nakanishi, 1989 and 1999: dotted line), and ARC-TR (Fukao, 1977: dash line). Model 12 is slightly modified from ARC-TR, and sn12c from model 12.

\section{Results for the Philippine Sea Regions}

Quantity and quality for the PHS and MAR datasets are lower than that for the NEJ, and we do not attempt to model velocity structures with any respective dataset. Signal-tonoise ratios of observed waveforms are lower in these two datasets and observed travel times show larger scatters as well (Figs. 6(b), (c)). Moreover, there is a gap in data, and we do not have observations at critical distances for triplicated branches. We then compare observations for these two paths with the predicted travel times from model sn12c to find the regional variations. Inferences from such comparison will be free from the assumptions that we use in modeling the velocity structure, and we could discuss the difference in structure in the upper mantle qualitatively. Data are processed in the similar manner as for the NEJ data set, and final datasets include picks from 175 events for the PHS path, and 172 events for the MAR path.

Compared to the Kurile-Alaska path, the Philippine Sea and the Mariana paths appear to be characterized by slightly lower velocities in the uppermost mantle and higher velocities in the transition zone and in the uppermost lower mantle. Although the scatter in the observation is large, predicted travel time from model sn $12 \mathrm{c}$ is smaller than observations between 10 and 15 degrees, and larger between 30 and 45 degrees (Figs. 6(b), (c)). Slow upper mantle for the Philippine Sea is consistent with the findings in the low-frequency seismology (Katzman et al., 1998; Kato and Jordan, 1999) as well as global tomographic models with high-frequency phase delays (e.g., Fukao et al., 1992). High velocities in the transition zone beneath the Philippine Sea have been reported in the one-dimensional model (Kato and Jordan, 1999) as well as in three-dimensional tomographic models (Suetsugu and Nakanishi, 1987; van der Hilst et al., 1991; Fukao et al., 1992).

\section{Discussion}

Existence of a low-velocity zone beneath the matured oceanic basin has been the focus of several decades of researches in the northwestern Pacific region. While some models in this region have well-established low-velocity zones (Fukao, 1977; Erdögan and Nowack, 1993), model sn12c as well as its mother model 12 of Sugiyama and Nakanishi $(1989,1999)$ does not have a distinct lid; velocity increases smoothly between Moho and the 410-km discontinuity. Strong signature of the low-velocity zone such as shadow zone or discontinuous jump in travel time curve is not seen in our observations. Shallow structure is constrained by observations in the shortest epicentral range, but scatter in observations are large in this epicentral range. Sugiyama and Nakanishi $(1989,1999)$ showed that incoming directions of $P$ phases do not always propagate along the great circle that connects the network and events in such epicentral ranges, suggesting effects of lateral heterogeneity. Although the scatter in the data inhibits us from strongly concluding so, our observations do not appear to imply a well-established lid-low-velocity-zone contrast. A high-gradient zone above the $410-\mathrm{km}$ discontinuity is seen in model sn $12 \mathrm{c}$ (Fig. 7). This zone characterizes the oceanic upper mantle, and appears to be a signature of relatively high geotherm (Gaherty et al., 1999).

Model sn12c presented here is not a unique model and should be treated as a representative of a class of models. Sugiyama and Nakanishi $(1989,1999)$ performed a statistical test in their $\tau$-p inversion (Stark and Parker, 1987); the structure in the shallowest $200 \mathrm{~km}$ is fixed and the error bounds for the transition zone velocities are estimated from the scatter in their observations. Their results indicate that while velocity gradients above and in the transition zone are well constrained by the data, shifting the depths of the 410- and $660-\mathrm{km}$ discontinuities by \pm 20 and $\pm 35 \mathrm{~km}$, respectively, can be easily afforded, and they concluded that the difference in depths of the 660-km discontinuity in Model 12 (at approximately at $700 \mathrm{~km}$ ) and ARC-TR (between 630 and $670 \mathrm{~km}$ ) might be insignificant. We tested our model with a qualitative approach; a number of models are generated by slightly perturbing Model sn12c, and the predicted travel times are compared with the observations and the sn12c prediction. Our conclusion is similar to that of Sugiyama and Nakanishi (1988, 1999), that is, our regional travel time data bound the discontinuity depths weakly $( \pm \sim 30 \mathrm{~km})$ due to scatter in data at critical epicentral distances. Similarly, disagreement among previous models in the Northwest Pacific regions might be fictitious and might not reflect the regional variations. In most studies, travel times are picked from the composite record sections, or waveforms of more than one event that are recorded at a number of stations. When the number of events becomes large, the error in source locations would bias the identification of later branches. Use of large 
aperture arrays appears to be promising in reducing such bias, but, especially when inter-station distances are large, weak correlation of waveforms between adjacent stations, owing to the site effects (Kato et al., 2000), would be disadvantageous in identifying branches of later phases. Station corrections for the short-period waveforms (Yamazaki et al., 1996) should be still a difficulty for waveforms recorded in regional distances owing to the nature of complex wave field.

Lateral heterogeneity in the transition zone velocities has been reported for the Philippine Sea region (Brudzinski et al., 1997; Tajima and Grand, 1998; Nowack et al., 1999) so that it might be crude to discuss the structure in detail with our results from a one-dimensional approach. Nevertheless, our findings of high velocity anomaly in two paths qualitatively agree with high velocity anomalies that are found in other regional studies (e.g., Suetsugu and Nakanishi, 1987; van der Hilst et al., 1991; Fukao et al., 1992). High velocity anomaly in the transition zone beneath the Philippine Sea has been linked to the accumulation of subducted slab which do not penetrate into the lower mantle effectively (Okino et al., 1989; van der Hilst and Seno, 1993; Ohtaki and Kaneshima, 1994; Tajima and Grand, 1998). The origin of the high velocity anomalies could be both thermal and chemical considering the compositional difference between the oceanic plate and the ambient mantle (e.g., Gaherty et al., 1999).

\section{Concluding Remarks}

We investigated the upper mantle velocity structure in the western Pacific region using array recordings at MSAS. Direct and triplicated $P$ phases are picked up from waveform data, and upper mantle velocities in three regions are investigated from observed $\Delta-\mathrm{T}$ curve. First arrivals for the Kurile-Alaska path are satisfactorily explained by a standard travel time model for this region. Our observations of direct and triplicated $P$ branches are well explained by a velocity model sn12c, which is a slight modification of Model 12 (Sugiyama and Nakanishi, 1989 and 1999). No strong evidence for the low-velocity zone in the uppermost mantle is found for this region. For the Ryukyu-Taiwan-Philippine path and Izu-Bonin-Mariana path, construction of velocity models is impeded by the quality and quantity of data. Nevertheless, the observation implies a slow uppermost mantle and a fast transition zone and uppermost lower mantle in these regions. The differences in the velocity structure could be the outcome of the past activity of subduction in the Philippine Sea region.

Acknowledgments. Access to the waveform archive of MSAS was provided by courtesy of Matsushiro Observatory, JMA. We would like to thank the staff at the Observatory, especially Akio Kobayashi and Hiroyuki Takayama, for their assistance and kindness. Akira Yamada, Takehi Isse, and Noriaki Serizawa assisted the data editing. We are grateful to anonymous reviewers for making constructive comments. The GMT software package, freely distributed by Wessel and Smith (1995), was used in this study. MK was supported by JSPS through Research Fellowship for Young Scientists program. IN was supported by Yamada Science Foundation and Kurata Science Foundation. The manuscript was completed while MK was a COE postdoctoral researcher at ERI, Univ. Tokyo.

\section{References}

Asano, S., S. Kubota, H. Okada, M. Nogoshi, H. Suzuki, K. Ichikawa, and $\mathrm{H}$. Watanabe, Explosion seismic studies of the underground structure in the Matsushiro Earthquake swarm area, J. Phys. Earth, 17, 77-90, 1969 Bina, C. R., Mantle discontinuities, Rev. Geophys., 29, 783-793, 1991.

Brudzinski, M. R., W.-P. Chen, R. L. Nowack, and B.-S. Huang, Variation of $P$ wave speeds in the mantle transition zone beneath the northern Philippine Sea, J. Geophys. Res., 102, 11,815-11,827, 1997.

Erdögan, N. and R. L. Nowack, Slant-stack velocity analysis for onedimensional upper mantle structure using short-period data from MAJO, Pure Appl. Geophys., 141, 1-24, 1993.

Fukao, Y., Upper mantle P structure on the ocean side of the Japan-Kurile arc, Geophys. J. R. Astr. Soc., 50, 621-642, 1977.

Fukao, Y., M. Obayashi, H. Inoue, and M. Nenbai, Subducting slabs in the mantle transition zone, J. Geophys. Res., 97, 4809-4822, 1992.

Gaherty, J. B., T. H. Jordan, and L. S. Gee, Depth extent of polarization anisotropy in western Pacific upper mantle, J. Geophys. Res., 101, 22,291-22,309, 1996.

Gaherty, J. B., M. Kato, and T. H. Jordan, Seismological structure of the upper mantle: a regional comparison of seismic layering, Phys. Earth Planet. Int., 110, 21-41, 1999.

Hamada, K, Re-examination of travel time tables for local earthquakes, Pap. Meteorol. Geophys., 35, 109-167, 1984 (in Japanese with English abstract).

Hirth, G. and D. L. Kohlstedt, Water in the oceanic upper mantle: Implication for rheology, melt extraction, and the evolution of the lithosphere, Earth Planet. Sci. Lett., 144, 93-108, 1996.

Inatani, H. and K. Kurita, Upper mantle velocity structure beneath the Ryukyu-Taiwan arc, Zisin, II, 33, 37-49, 1980 (in Japanese with English abstract).

Ita, J. and L. Stixrude, Petrology, elasticity, and composition of the mantle transition zone, J. Geophys. Res., 97, 6849-6866, 1992.

Kanamori, H., Upper mantle structure from apparent velocities of $\mathrm{P}$ wave recorded at Wakayama Microearthquake Observatory, Bull. Earthq. Res. Inst., Univ. Tokyo, 45, 657-678, 1967.

Karato, S.-I., Effect of water on seismic wave velocities in the upper mantle, Proc. Japan Academy, 71, Ser. B, 61-66, 1995.

Kato, M. and T. H. Jordan, Seismic structure of the upper mantle beneath the western Philippine Sea, Phys. Earth Planet. Int., 110, 263-283, 1999.

Kato, M., I. Nakanishi, and H. Takayama, Isolation of local site characteristics from teleseismic short-period recordings at Matsushiro Seismic Array System, Bull. Seis. Soc. Am., 2000 (submitted).

Katzman, R., L. Zhao, and T. H. Jordan, High-resolution, two-dimensional vertical tomography of the central Pacific mantle using ScS reverberations and frequency-dependent travel times, J. Geophys. Res., 103, 17,933$17,971,1998$

Kishimoto, Y., Seismometric investigation of the earth's interior, Part 3. On the structure of the earth's mantle (I), Mem. Coll. Sci. Kyoto Univ., Ser. A., 28, 117-142, 1956.

Maki, T., S. Kashiwabara, Y. Osada, M. Nishiwaki, T. Kakishita, and S. Nagare, Determination of apparent velocities and azimuths of distant earthquakes by the Matsushiro Seismic Array System - Effect of dipping structure of the crust and near-surface-, Tech. Rep. Seis. Obs., Japan Meteorol. Agency, 8, 1-21, 1987 (in Japanese with English abstract).

Nagai, A. and S. Kashiwabara, Underground structure under the Matsushiro Seismic Array System, Tech. Rep. Seis. Obs., Japan Meteorol. Agency, 6, 54-60, 1985 (in Japanese with English abstract).

Niazi, M. and D. Anderson, Upper mantle structure of the earth's upper mantle from apparent velocities of $P$ waves, J. Geophys. Res., 70, 46224640, 1965.

Nolet, G., S. P. Grand, and B. L. N. Kennett, Seismic heterogeneity in the upper mantle, J. Geophys. Res., 99, 23,753-23,766, 1994

Nowack, R. L., E. Ay, W.-P. Chen, and B.-S. Huang, A seismic profile of the upper mantle along the southwestern edge of the Philippine Sea plate using short-period array data, Geophys. J. Int., 136, 171-179, 1999.

Ohtaki, T. and S. Kaneshima, Continuous high velocity aseismic zone beneath the Izu-Bonin Arc, Geophys. Res. Lett., 21, 1-4, 1994.

Okino, K., M. Ando, S. Kaneshima, and K. Hirahara, The horizontally lying slab, Geophys. Res. Lett., 16, 1059-1062, 1989.

Osada, Y., S. Kashiwabara, A. Nagai, H. Takayama, S. Wakui, I. Morishita, and Y. Tanaka, Matsushiro Seismic Array System (I)-Outline and hypocenter determination of near earthquakes, Tech. Rep. Seis. Obs., Japan Meteorol. Agency, 5, 13-31, 1984 (in Japanese with English abstract).

Ringwood, A. E., Composition and petrology of the Earth's mantle, 604 pp., McGraw-Hill, New York, 1975.

Sato, H., I. S. Sacks, and T. Murase, The use of laboratory velocity data for estimating temperature and partial melt fraction in the low-velocity 
zone: Comparison with heat flow and electrical conductivity studies, $J$. Geophys. Res., 94, 5689-5704, 1989.

Stark, P. B. and R. L. Parker, Velocity bounds from statistical estimates of $\tau(\mathrm{p})$ and X(p), J. Geophys. Res., 92, 2713-2719, 1987.

Su, W.-J., R. L. Woodward, and A. M. Dziewonski, Degree 12 model of shear velocity heterogeneity in the mantle, J. Geophys. Res., 99, 6945-6980, 1994.

Suetsugu, D. and I. Nakanishi, Three-dimensional velocity map of the upper mantle beneath the Pacific Ocean as determined from Rayleigh wave dispersion, Phys. Earth Planet. Int., 47, 205-229, 1987.

Sugiyama, T. and I. Nakanishi, Upper mantle P-wave structure of the northwestern rim of the Pacific Ocean, Progr. Abs. Seismo. Soc. Japan, 1, 204, 1989 (in Japanese).

Sugiyama, T. and I. Nakanishi, Upper mantle P-wave structure of the northwestern rim of the Pacific Ocean, Mem. Fac. Sci., Kyoto Univ., Ser. phys. astrophys. geophys. chem, 1999 (submitted).

Tajima, F. and S. P. Grand, Evidence of high velocity anomalies in the transition zone associated with southern Kurile subduction zone, Geophys. Res. Lett., 22, 3139-3142, 1995.

Tajima, F. and S. P. Grand, Variation of transition zone high-velocity anomalies and depression of $660 \mathrm{~km}$ discontinuity associated with subduction zones from the southern Kuriles to Izu-Bonin and Ryukyu, J. Geophys. Res., 103, 15,015-15,036, 1998.

Turcotte, D. L. and G. Schubert, Geodynamics: applications of continuum physics to geological problems, 450 pp., John Wiley and Sons, New York,
1982

van der Hilst, R. D., R. Engdahl, W. Spakman, and G. Nolet, Tomographic imaging of subducted lithosphere below northwest Pacific island arcs, Nature, 353, 37-43, 1991.

van der Hilst, R. D. and T. Seno, Effect of relative plate motion on the deep structure and penetration depth of slabs below the Izu-Bonin and Mariana islands arc, Earth Planet. Sci. Lett., 120, 395-407, 1993.

Walck, M. C., The P-wave upper mantle structure beneath an active spreading centre: The Gulf of California, Geophys. J. R. Astr. Soc., 76, 697-723, 1984

Walck, M. C., The P-wave upper mantle structure beneath the northwest Pacific rim: A comparison with the Gulf of California. Geophys. J. R. Astr. Soc., 81, 243-276, 1985.

Wessel, P. and W. H. F. Smith, New version of the Generic Mapping Tools released, Eos Trans. AGU, 76, 329, 1995.

Yamazaki, A. and K. Hirahara, The upper-mantle P-wave velocity structure beneath the Northern Japan Arc, as inferred from J-Array data, J. Phys. Earth, 44, 713-728, 1996.

Yamazaki, A., K. Hirahara, and T. Shibutani, Waveform station anomaly -Definition and example for J-Array stations-, J. Phys. Earth, 44, 675-685, 1996.

M. Kato (e-mail: mkato@eri.u-tokyo.ac.jp) and I. Nakanishi 